Check for updates

Cite this: RSC Adv., 2019, 9, 1362

Received 12th December 2018 Accepted 2nd January 2019

DOI: $10.1039 / c 8 r a 10212 k$

rsc.li/rsc-advances

\section{A new bifunctional heterogeneous nanocatalyst for one-pot reduction-Schiff base condensation and reduction-carbonylation of nitroarenes}

\begin{abstract}
Sara Sobhani, (D) *a Farhad Omarzehi Chahkamali ${ }^{\mathrm{a}}$ and José Miguel Sansano (iD ${ }^{\mathrm{b}}$
In this work, synthesis of $\mathrm{Pd}-\mathrm{NHC}-\gamma-\mathrm{Fe}_{2} \mathrm{O}_{3}-n$-butyl- $\mathrm{SO}_{3} \mathrm{H}$ and its activity as a bifunctional heterogeneous nanocatalyst containing $\mathrm{Pd}-\mathrm{NHC}$ and acidic functional groups, are described. This newly synthesized nanomagnetic catalyst is fully characterized by different methods such as FT-IR, XPS, TEM, VSM, ICP and $\mathrm{TG}$ analysis. At first, the catalytic activity of $\mathrm{Pd}-\mathrm{NHC}-\gamma-\mathrm{Fe}_{2} \mathrm{O}_{3}-n$-butyl- $\mathrm{SO}_{3} \mathrm{H}$ is evaluated for the reduction of nitroarenes in aqueous media using $\mathrm{NaBH}_{4}$ as a clean source of hydrogen generation at ambient temperature. Using the promising results obtained from the nitroarene reduction, this catalytic system is used for two one-pot protocols including reduction-Schiff base condensation and reductioncarbonylation of various nitroarenes. In these reactions the in situ formed amines are further reacted with aldehydes to yield imines or carbonylated to amides. The desired products are obtained in good to high yields in the presence of $\mathrm{Pd}-\mathrm{NHC}-\gamma-\mathrm{Fe}_{2} \mathrm{O}_{3}-n$-butyl $-\mathrm{SO}_{3} \mathrm{H}$ as a bifunctional catalyst. The catalyst is reused with the aid of a magnetic bar for up to six consecutive cycles without any drastic loss of its catalytic activity.
\end{abstract}

\section{Introduction}

Polyfunctional catalysis, that enables one-pot multistep reactions, holds great potential for increasing the efficiency of chemical synthesis. Performing multiple reactions in a single reaction vessel is a sustainable process avoiding intermediate separation, purification steps, and minimizing energy and increased safety as well as manipulation of equilibria. ${ }^{1}$ By mimicking biological systems, some research groups have focused their attention in the design and synthesis of catalysts that contain multiple types of active centers to promote domino reactions. ${ }^{2}$ These functionalities act in a cooperative way to provide reactivity and selectivity superior to what can be obtained from monofunctionalized materials. This strategy brings to mind enzymes as biological catalysts, which accelerate and control the selectivity of chemical transformations by different active centers. ${ }^{3}$ A series of examples have been recently reported for the synthesis of acids and bases on solid supports for dual activation of electrophiles and nucleophiles. ${ }^{4}$ However, systematic investigations as well as the successful cohabitation of metal and acid functionalities on a single solid support and the evaluation of the catalytic activity of such systems in one-pot reactions are rare in the literature.

Over the last few decades, N-heterocyclic carbenes (NHCs) have emerged as an extremely useful, new and versatile class of

${ }^{a}$ Department of Chemistry, College of Sciences, University of Birjand, Birjand, Iran. E-mail: ssobhani@birjand.ac.ir; sobhanisara@yahoo.com

${ }^{b}$ Departamento de Química Orgánica, Facultad de Ciencias, Centro de Innovación en Química Avanzada (ORFEO-CINQA) and Instituto de Sintesis Orgánica (ISO), Universidad de Alicante, Apdo. 99, 03080-Alicante, Spain ligands in transition metal catalysis due to the stability in air and moisture and also strong s-electron-donating properties, which allow effective and strong NHC-metal bonds with numerous transition metals. ${ }^{5}$ NHC-chelated transition metals have been used in several types of homogeneous catalytic reactions, such as $\mathrm{C}-\mathrm{C}$ coupling, reduction and $\mathrm{C}-\mathrm{N}$ bond formation reactions. ${ }^{6}$ Since NHC-chelated transition metals contain expensive ligands and heavy metals, heterogenized NHC metal complexes are attractive because of their reusability and preventing of product contamination with traces of heavy metals. ${ }^{7}$ One way to prepare heterogeneous NHC metal complexes is their immobilization on different solid supports through their nitrogen. For instance, polystyrene, iron oxide, graphene oxide or silica have been reported for the immobilization of NHC metal complexes. ${ }^{8}$ The presence of nitrogen atoms in NHC ligands is also very useful for functionalization of NHC ligands to obtain bifunctional NHC metal complexes. NHC-based bifunctional catalysts with latetransition metals like $\mathrm{Ni}, \mathrm{Rh}, \mathrm{Ru}$ and $\mathrm{Ir}$ have been developed for a variety of important reactions like Michael addition, alkylations of amines with alcohols, hydration of organonitriles, hydrogenation of esters and ketones, etc. ${ }^{9}$ Although, NHCs have long become popular as ligands of choice in transition metal mediated catalysis, their related utility in bifunctional catalysis remains surprisingly overlooked. Therefore, bifunctional catalysis of the NHC-based systems is still in its developmental stage and thereby there is a leaving room for development of other transition metals of NHC-based bifunctional catalysts for important organic transformations.

Compounds containing nitro groups are the most readily available starting materials in organic synthesis. One of the 
major applications of nitroarenes in organic transformations is their hydrogenation to afford anilines. ${ }^{\mathbf{1 0}}$ Anilines are highly versatile building blocks for various substrates. One of the aniline derivatives is imines, which are versatile intermediates in organic synthesis and prepared generally by the reaction of amines and carbonyl compounds. Recently, few methods for domino nitroarene reduction and intramolecular Schiff base condensation in the presence of $\mathrm{Au} / \mathrm{TiO}_{2} / \mathrm{H}_{2},{ }^{11} \mathrm{Fe} / \mathrm{HCl},{ }^{12} \mathrm{Se} /$ $\mathrm{NaOAc} / \mathrm{CO},{ }^{13} \mathrm{Ni} / \mathrm{SiO}_{2} / \mathrm{H}_{2},{ }^{14} \mathrm{CoO}_{x} @ \mathrm{NC}-800 / \mathrm{H}_{2}{ }^{15}$ have been reported for the one-pot synthesis of imines. These protocols start from nitroarenes and require special equipment to handle high pressure inflammable hydrogen gas, hazardous carbon monoxide or highly acidic conditions, elevated pressures and high temperatures. These requirements made the reported methods far from ideal for laboratory-scale synthetic chemistry.

Amides, as the other derivatives of amines, occupy pivotal positions in organic synthesis. Generally, amides are produced through the reaction of carboxylic acids or esters with amines. As nitroarenes are readily available chemicals in industry, conversion of nitroarenes directly to their corresponding amides in one-pot reduction-carbonylation reactions is more efficient than starting from the corresponding amine. ${ }^{16}$ This protocol generally involves two steps; the first step is the reduction of nitroarenes to the corresponding anilines and the second step is the carbonylation of anilines to the corresponding amides. Indium/AcOH $,{ }^{17} \mathrm{Ni}_{2} \mathrm{~B} @ \mathrm{Cu}_{2} \mathrm{O} / \mathrm{NaBH}_{4},{ }^{18} \mathrm{Pd}-\mathrm{C} /$ $\mathrm{NaBH}_{4}{ }^{19}$ and $\mathrm{Fe}_{3} \mathrm{O}_{4} @ \mathrm{Cu}(\mathrm{OH})_{x} / \mathrm{NaBH}_{4}{ }^{20}$ are some of the systems which have been reported for direct transformation of nitroarenes to amides. Although most of the published methods are useful synthetic methods, they generally suffer from long reaction times, unsatisfactory yields of the products and use of unrecoverable catalysts. Thus, an alternative method which is effective, simple, green, employing reusable catalysts would be a subject of interest. Continuing with the aim of our recent works on the introduction of new heterogeneous Pd-catalysts, ${ }^{21}$ herein, we wish to report the synthesis of a new Pd-NHC complex containing an acidic functional group immobilized on $\gamma-\mathrm{Fe}_{2} \mathrm{O}_{3}$ (Pd-NHC- $\gamma-\mathrm{Fe}_{2} \mathrm{O}_{3}-n$-butyl-SO $\left.\mathrm{S}_{3} \mathrm{H}\right)$ as a bifunctional heterogeneous nanocatalyst. After characterization of this catalyst, its catalytic activity was evaluated for the reduction of nitrobenzenes using $\mathrm{NaBH}_{4}$ in water as a green solvent at ambient temperature. By the promising results obtained from nitroarene reduction, this catalytic system was used for two onepot protocols including reduction-Schiff base condensation and reduction-carbonylation of various nitroarenes. The process involved reduction of the correspondent nitro compounds to anilines in the presence of the Pd-catalyst and then reaction of anilines with the carbonyl compounds or anhydrides catalyzed by acidic functional group of $\mathrm{Pd}-\mathrm{NHC}-\gamma-\mathrm{Fe}_{2} \mathrm{O}_{3}-n$-butyl- $\mathrm{SO}_{3} \mathrm{H}$ to give imines and amides, respectively.

\section{Results and discussion}

\section{Synthesis and characterization of Pd-NHC- $\gamma-\mathrm{Fe}_{2} \mathrm{O}_{3}$-n-butyl- $\mathrm{SO}_{3} \mathrm{H}$}

Scheme 1 describes the synthetic procedure to prepare $\mathrm{Pd}-$ $\mathrm{NHC}-\gamma-\mathrm{Fe}_{2} \mathrm{O}_{3}-n$-butyl- $\mathrm{SO}_{3} \mathrm{H}$. At first, $\gamma-\mathrm{Fe}_{2} \mathrm{O}_{3}$ was functionalized

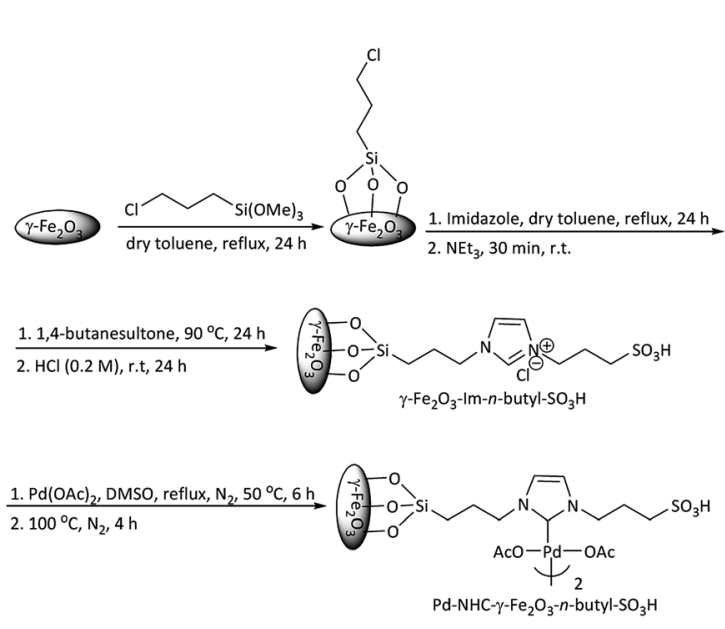

Scheme 1 Synthesis of $\mathrm{Pd}-\mathrm{NHC}-\gamma-\mathrm{Fe}_{2} \mathrm{O}_{3}-n$-butyl- $\mathrm{SO}_{3} \mathrm{H}$.

by 3-chlorotrimethoxypropylsilane and reacted with imidazole. After neutralization with $\mathrm{Et}_{3} \mathrm{~N}, \gamma-\mathrm{Fe}_{2} \mathrm{O}_{3}$-Im was obtained. Reaction of $\gamma-\mathrm{Fe}_{2} \mathrm{O}_{3}$-Im with 1,4-butanesultone and then acidification with $\mathrm{HCl}(0.2 \mathrm{M})$ produced $\gamma-\mathrm{Fe}_{2} \mathrm{O}_{3}-\mathrm{Im}-n$-butyl- $\mathrm{SO}_{3} \mathrm{H}$. Finally, Pd-NHC- $\gamma-\mathrm{Fe}_{2} \mathrm{O}_{3}-n$-butyl- $\mathrm{SO}_{3} \mathrm{H}$ was obtained from the reaction of $\gamma-\mathrm{Fe}_{2} \mathrm{O}_{3}$-Im- $n$-butyl- $\mathrm{SO}_{3} \mathrm{H}$ with $\mathrm{Pd}(\mathrm{OAc})_{2}$.

Chemical structures of all the synthesized compounds were confirmed through the FT-IR spectroscopic technique. Fig. 1 demonstrates FT-IR spectra of $\gamma$ - $\mathrm{Fe}_{2} \mathrm{O}_{3}$-Im (a), $\gamma$ - $\mathrm{Fe}_{2} \mathrm{O}_{3}$-Im- $n$-butyl$\mathrm{SO}_{3} \mathrm{H}$ (b) and $\mathrm{Pd}-\mathrm{NHC}-\gamma-\mathrm{Fe}_{2} \mathrm{O}_{3}-n$-butyl- $\mathrm{SO}_{3} \mathrm{H}$ (c). These spectra displayed a characteristic peak of $\mathrm{Fe}-\mathrm{O}$ at around $555-676 \mathrm{~cm}^{-1}$ and stretching vibrations of $\mathrm{O}-\mathrm{H}$ bonds at $3436 \mathrm{~cm}^{-1}$. The bands observed around 1068, 2927, 3141 and $1560 \mathrm{~cm}^{-1}$ are attributed to the $\mathrm{Si}-\mathrm{O}$, aliphatic and aromatic $\mathrm{C}-\mathrm{H}$ and $\mathrm{C}=\mathrm{C}$ stretching vibrations, which confirm the functionalization of the surface of the MNPs. The FT-IR spectra of $\gamma-\mathrm{Fe}_{2} \mathrm{O}_{3}$-Im-butyl- $\mathrm{SO}_{3} \mathrm{H}$ (b) and Pd$\mathrm{NHC}-\gamma-\mathrm{Fe}_{2} \mathrm{O}_{3}-n$-butyl- $\mathrm{SO}_{3} \mathrm{H}$ (c) exhibit a typical band at around $1040 \mathrm{~cm}^{-1}$ attributed to $\mathrm{S}=\mathrm{O}$ stretching vibrations (Fig. 1).

XPS study was carried out to check the surface chemical compositions of Pd-NHC- $\gamma-\mathrm{Fe}_{2} \mathrm{O}_{3}-n$-butyl- $\mathrm{SO}_{3} \mathrm{H}$ (Fig. 2). The peaks corresponding to oxygen, carbon, nitrogen, silicon, iron and sulfur are clearly observed in the XPS elemental survey of the catalyst (Fig. 2a). Deconvolution of $\mathrm{C} 1 \mathrm{~s}$ region showed a major peak at $284.6 \mathrm{eV}$ corresponding to $\mathrm{C}-\mathrm{C}$ and $\mathrm{C}=\mathrm{C}$

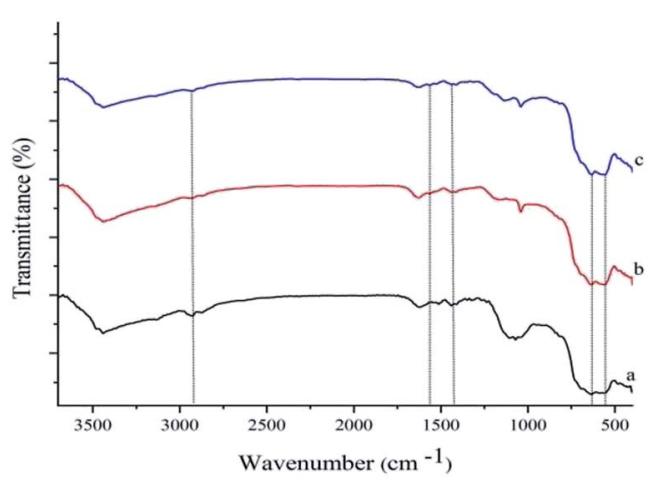

Fig. 1 FT-IR spectra of (a) $\gamma-\mathrm{Fe}_{2} \mathrm{O}_{3}-\mathrm{Im}$, (b) $\gamma-\mathrm{Fe}_{2} \mathrm{O}_{3}-\mathrm{Im}$ - $n$-butyl- $\mathrm{SO}_{3} \mathrm{H}$ and (c) $\mathrm{Pd}-\mathrm{NHC}-\gamma-\mathrm{Fe}_{2} \mathrm{O}_{3}-n$-butyl- $\mathrm{SO}_{3} \mathrm{H}$. 

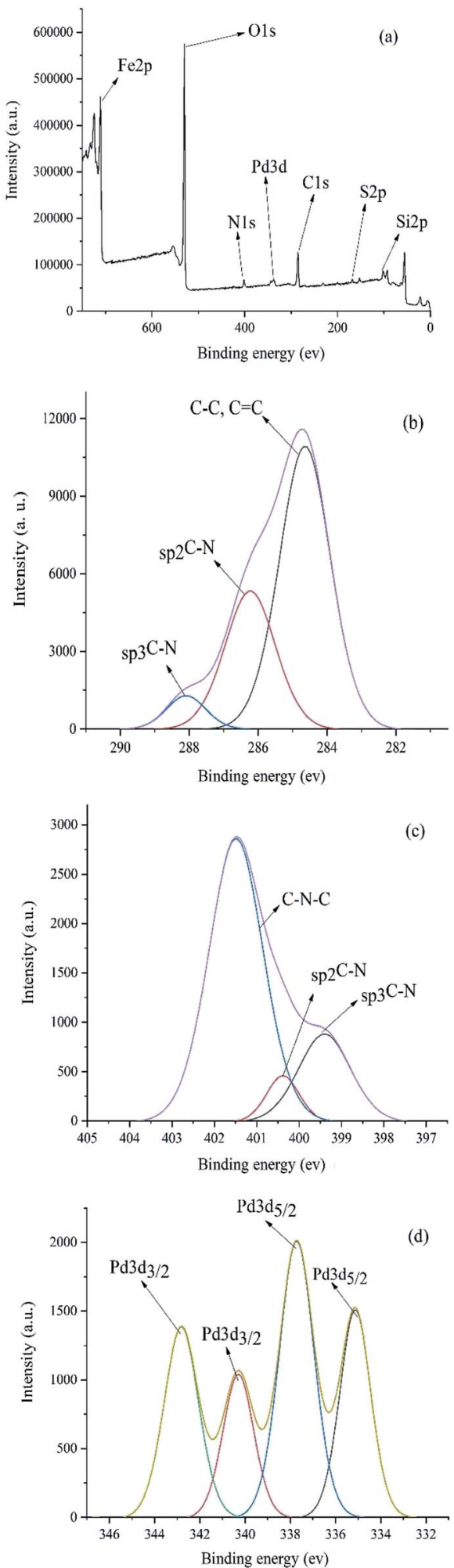

Fig. 2 (a) XPS patterns of the $\mathrm{Pd}-\mathrm{NHC}-\gamma-\mathrm{Fe}_{2} \mathrm{O}_{3}-n$-butyl- $\mathrm{SO}_{3} \mathrm{H}$ nanomagnetic catalyst (b) $\mathrm{C}$ 1s (c) $\mathrm{N}$ 1s (d) Pd.

(Fig. 2b). In addition, the peaks observed at $286.2 \mathrm{eV}$ and $288.0 \mathrm{eV}$ refer to the $\mathrm{C}_{\mathrm{sp}^{2}}-\mathrm{N}$ and $\mathrm{C}_{\mathrm{sp}^{3}}-\mathrm{N}$ bonds, respectively. Fig. 2c showed the nitrogen region of the XPS measured spectrum for the $\mathrm{Pd}-\mathrm{NHC}-\gamma-\mathrm{Fe}_{2} \mathrm{O}_{3}-n$-butyl- $\mathrm{SO}_{3} \mathrm{H}$. It revealed the presence of a main peak at $401.4 \mathrm{eV}$ related to $\mathrm{C}-\mathrm{N}-\mathrm{C}$ and two more peaks at 399.4 and $400.3 \mathrm{eV}$ related to $\mathrm{C}_{\mathrm{sp} 3}-\mathrm{N}$ and $\mathrm{C}_{\mathrm{sp} 2}-\mathrm{N}$, respectively. ${ }^{22}$ As shown in Fig. 2d, the peaks at 337.7 (3d5/2) and $342.8 \mathrm{eV}(3 \mathrm{~d} 3 / 2)$, correspond to Pd with II oxidation state. The peaks at $335.1(3 \mathrm{~d} 5 / 2)$ and $340.3 \mathrm{eV}(3 \mathrm{~d} 3 / 2)$ indicate that a small portion of Pd is in zero oxidation state. ${ }^{8 c}$

The Pd content of Pd-NHC- $\gamma-\mathrm{Fe}_{2} \mathrm{O}_{3}-n$-butyl- $\mathrm{SO}_{3} \mathrm{H}$ was quantified by ICP. The ICP analysis showed that $0.21 \mathrm{mmol}$ of Pd was anchored onto $1 \mathrm{~g}$ of $\mathrm{Pd}-\mathrm{NHC}-\gamma-\mathrm{Fe}_{2} \mathrm{O}_{3}-n$-butyl- $\mathrm{SO}_{3} \mathrm{H}$. The particle size distribution of $\mathrm{Pd}-\mathrm{NHC}-\gamma-\mathrm{Fe}_{2} \mathrm{O}_{3}-n$-butyl- $\mathrm{SO}_{3} \mathrm{H}$ was evaluated using TEM, which demonstrated that the average diameter of the particles was $17 \mathrm{~nm}$. TEM images also showed that the NPs are spherical in shape and are relatively monodispersed (Fig. 3).

The magnetic properties of Pd-NHC- $\gamma-\mathrm{Fe}_{2} \mathrm{O}_{3}-n$-butyl- $\mathrm{SO}_{3} \mathrm{H}$ and $\gamma-\mathrm{Fe}_{2} \mathrm{O}_{3}$ were evaluated by VSM at room temperature (Fig. 4). The saturation magnetization value of $\mathrm{Pd}-\mathrm{NHC}-\gamma$ $\mathrm{Fe}_{2} \mathrm{O}_{3}$ - $n$-butyl-SO $\mathrm{S}_{3} \mathrm{H}$ was $65.9 \mathrm{emu} \mathrm{g}^{-1}$, which is similar to that of
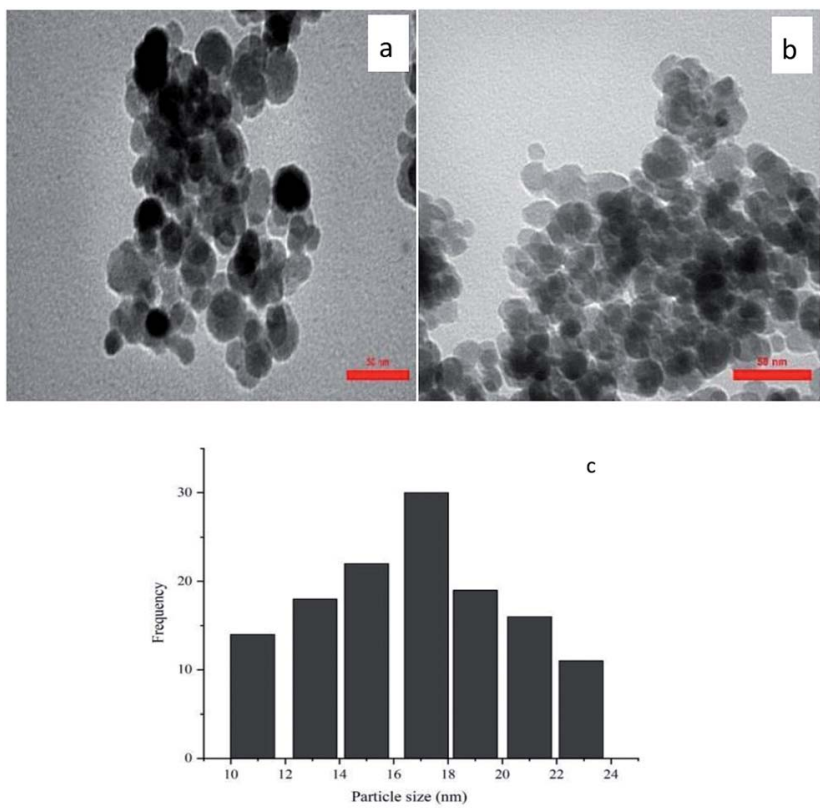

Fig. 3 ( $a$ and b) TEM and (c) particle size distribution histogram of $\mathrm{Pd}-$ $\mathrm{NHC}-\gamma-\mathrm{Fe}_{2} \mathrm{O}_{3}-n$-butyl- $\mathrm{SO}_{3} \mathrm{H}$.

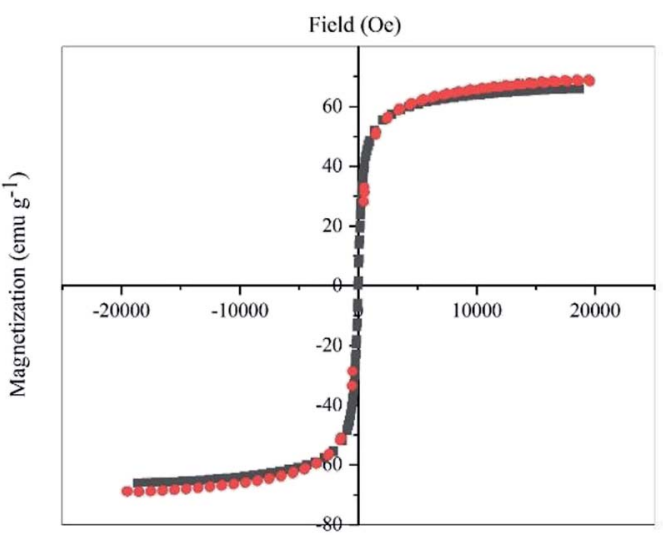

Fig. 4 Magnetization curves $\gamma-\mathrm{Fe}_{2} \mathrm{O}_{3}$ (red) and $\mathrm{Pd}-\mathrm{NHC}-\gamma-\mathrm{Fe}_{2} \mathrm{O}_{3}-n-$ butyl- $\mathrm{SO}_{3} \mathrm{H}$ (black). 


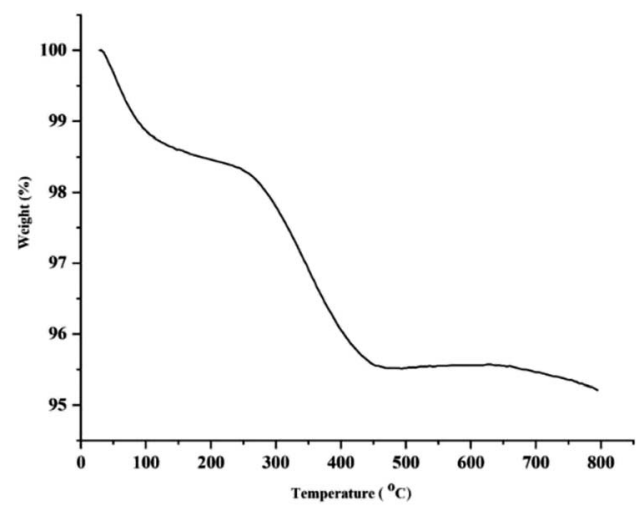

Fig. 5 TGA curve of $\mathrm{Pd}-\mathrm{NHC}-\gamma-\mathrm{Fe}_{2} \mathrm{O}_{3}-n$-butyl- $\mathrm{SO}_{3} \mathrm{H}$.

$\gamma-\mathrm{Fe}_{2} \mathrm{O}_{3}$ (68.6 emu g $\left.{ }^{-1}\right)$. Small decrease in the saturated magnetization value of $\mathrm{Pd}-\mathrm{NHC}-\gamma-\mathrm{Fe}_{2} \mathrm{O}_{3}-n$-butyl- $\mathrm{SO}_{3} \mathrm{H}$ compared to that of $\gamma-\mathrm{Fe}_{2} \mathrm{O}_{3}$ can be attributed to the slight increase in mass owing to the immobilized Pd-complex on the surface of $\gamma-\mathrm{Fe}_{2} \mathrm{O}_{3}$. The magnetization curves showed no hysteresis loop, which indicated superparamagnetic characteristic of the nanoparticles. The strong magnetic properties of the nanoparticles were sufficient for complete and easy magnetic separation with attraction to a conventional magnet.

Fig. 5 shows the TG analysis of Pd-NHC- $\gamma-\mathrm{Fe}_{2} \mathrm{O}_{3}-n$-butyl$\mathrm{SO}_{3} \mathrm{H}$. The thermogravimetric analysis exhibited the first weight loss of $1.45 \%$ below $168{ }^{\circ} \mathrm{C}$, which might be due to the loss of physically adsorbed water adhering to the sample surface and surface hydroxyl groups. The second weight loss between 168 and $488^{\circ} \mathrm{C}(3 \%)$ was due to the breakdown and decomposition of imidazole moieties. Thus, the TG curves also convey the obvious information that the imidazole molecules are successfully grafted onto the magnetic nanoparticles.

\section{Catalytic performance of Pd-NHC- $\boldsymbol{\gamma}-\mathrm{Fe}_{2} \mathrm{O}_{3}-\boldsymbol{n}$-butyl- $\mathrm{SO}_{3} \mathrm{H}$}

In order to investigate the catalytic activity of Pd-NHC- $\gamma-\mathrm{Fe}_{2} \mathrm{O}_{3}-$ $n$-butyl- $\mathrm{SO}_{3} \mathrm{H}$ as a bifunctional heterogeneous catalyst for the one-pot reduction-Schiff base condensation and one-pot reduction-carbonylation of various nitroarenes, we have initially evaluated the efficiency of the catalyst for the reduction of nitroarenes by $\mathrm{NaBH}_{4}$ as a clean source of hydrogen generation. For this purpose, the reduction of nitrobenzene at room temperature was chosen as a model reaction to optimize the reaction conditions such as solvent and the amount of the catalyst (Table 1). As indicated in Table 1, aqueous media and $0.6 \mathrm{~mol} \%$ of the catalyst are the best choice of these reactions (Table 1, entry 3 ). Increasing the amount of the catalyst to 0.8 and $1 \mathrm{~mol} \%$ did not produce any effect on the yield of the desired product (Table 1, entries 4 and 5). The reaction proceeded smoothly in the presence of lower amounts of the catalyst (Table 1, entries 1 and 2). Other organic solvents such as EtOH and $\mathrm{MeOH}$ afforded the desired product in longer reaction time and lower yields (Table 1, entries 6 and 9). It was observed that the product was obtained in higher yield when a mixture of EtOH and water $(1: 1$ and $1: 4)$ was used as solvent (Table 1, entries 7 and 8). This phenomenon could be attributed to the property of greater activity of $\mathrm{NaBH}_{4}$ in water. In the absence of solvent, the reaction did not proceed at all, even after $24 \mathrm{~h}$ (Table 1, entry 10).

We next examined the reduction of a variety of nitroarenes by $\mathrm{NaBH}_{4}$ under the optimized reaction conditions. The results of this study are depicted in Table 2 . The reaction of different nitroarenes with electron-releasing or electron-withdrawing groups proceeded well in the presence of Pd-NHC- $\gamma-\mathrm{Fe}_{2} \mathrm{O}_{3}-n-$ butyl- $\mathrm{SO}_{3} \mathrm{H}(0.6 \mathrm{~mol} \%)$ and the desired products were obtained in $70-99 \%$ yields in $20-60 \mathrm{~min}$.

A significant practical advantage of heterogeneous catalysis is the ability to easily remove the catalyst from the reaction mixture and reuse it for subsequent reactions. In this regard, the recycling and reusing capability of the catalyst was investigated in the reduction reaction of nitrobenzene with $\mathrm{NaBH}_{4}$, under optimum reaction conditions, in the presence of Pd$\mathrm{NHC}-\gamma-\mathrm{Fe}_{2} \mathrm{O}_{3}-n$-butyl- $\mathrm{SO}_{3} \mathrm{H}$. After reaction, the catalyst was completely collected from the reaction mixture using an

Table 1 Reduction of nitrobenzene to aniline with $\mathrm{NaBH}_{4}$ catalyzed by $\mathrm{Pd}-\mathrm{NHC}-\gamma-\mathrm{Fe}_{2} \mathrm{O}_{3}-n$-butyl-SO $\mathrm{H}_{3}$ under different conditions ${ }^{a}$

$$
\frac{\mathrm{Pd}-\mathrm{NHC}-\gamma-\mathrm{Fe}_{2} \mathrm{O}_{3}-n \text {-butyl- } \mathrm{SO}_{3} \mathrm{H}}{\mathrm{NaBH}_{4} \text {, solvent, r.t. }}
$$

\begin{tabular}{|c|c|c|c|c|}
\hline 1 & $\mathrm{H}_{2} \mathrm{O}$ & $\mathrm{Pd}-\mathrm{NHC}-\gamma-\mathrm{Fe}_{2} \mathrm{O}_{3}-n$-butyl- $\mathrm{SO}_{3} \mathrm{H}(0.3)$ & 60 & 95 \\
\hline 2 & $\mathrm{H}_{2} \mathrm{O}$ & $\mathrm{Pd}-\mathrm{NHC}-\gamma-\mathrm{Fe}_{2} \mathrm{O}_{3}-n$-butyl- $\mathrm{SO}_{3} \mathrm{H}(0.5)$ & 40 & 95 \\
\hline 4 & $\mathrm{H}_{2} \mathrm{O}$ & Pd-NHC- $\gamma-\mathrm{Fe}_{2} \mathrm{O}_{3}-n$-butyl- $\mathrm{SO}_{3} \mathrm{H}(0.8)$ & 25 & 97 \\
\hline 5 & $\mathrm{H}_{2} \mathrm{O}$ & $\mathrm{Pd}-\mathrm{NHC}-\gamma-\mathrm{Fe}_{2} \mathrm{O}_{3}-n$-butyl- $\mathrm{SO}_{3} \mathrm{H}(1)$ & 20 & 98 \\
\hline 6 & EtOH & $\mathrm{Pd}-\mathrm{NHC}-\gamma-\mathrm{Fe}_{2} \mathrm{O}_{3}-n$-butyl- $\mathrm{SO}_{3} \mathrm{H}(0.6)$ & $5 \mathrm{~h}$ & 25 \\
\hline 9 & $\mathrm{MeOH}$ & $\mathrm{Pd}-\mathrm{NHC}-\gamma-\mathrm{Fe}_{2} \mathrm{O}_{3}-n$-butyl- $\mathrm{SO}_{3} \mathrm{H}(0.6)$ & $5 \mathrm{~h}$ & 90 \\
\hline 10 & - & Pd-NHC- $\gamma-\mathrm{Fe}_{2} \mathrm{O}_{3}-n$-butyl- $\mathrm{SO}_{3} \mathrm{H}(0.6)$ & $24 \mathrm{~h}$ & 0 \\
\hline
\end{tabular}


Table 2 Reduction of nitroarenes by $\mathrm{NaBH}_{4}$ catalyzed by $\mathrm{Pd}-\mathrm{NHC}-\gamma-\mathrm{Fe}_{2} \mathrm{O}_{3}-n$-butyl- $\mathrm{SO}_{3} \mathrm{H}$ in aqueous media at ambient temperature

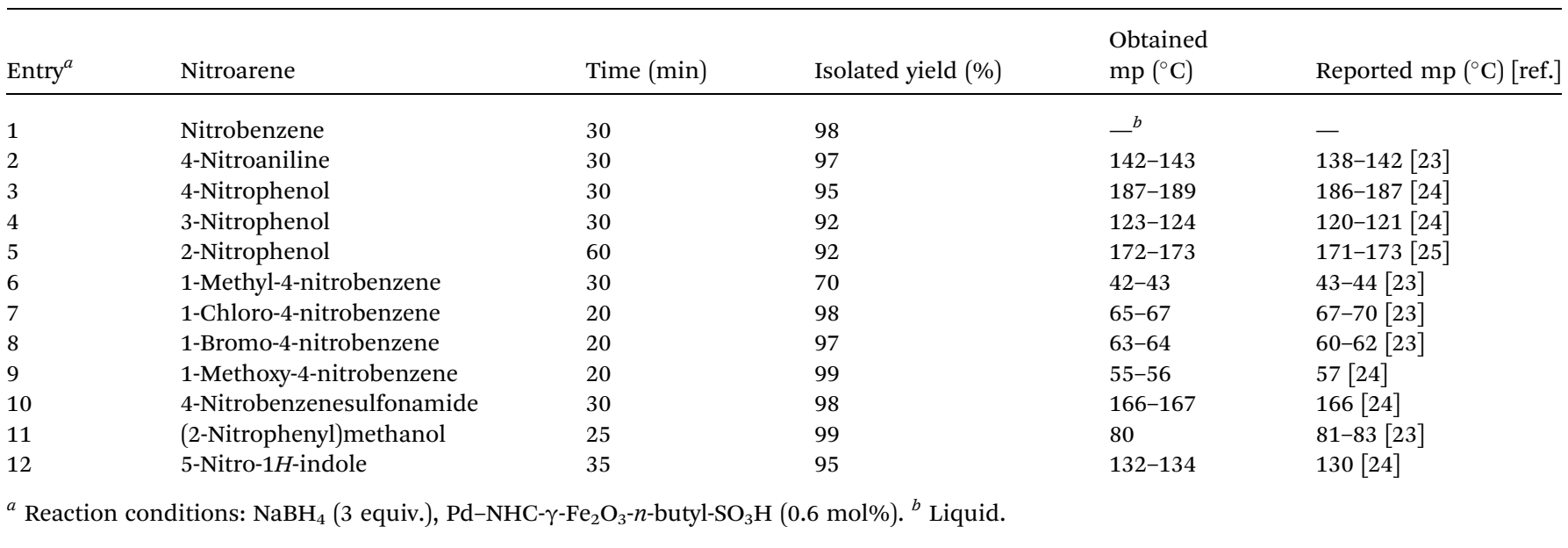

external magnet. This catalyst was exhaustively washed with water and acetone in sequence. Then, it was dried and used directly for the next run under the same conditions. Other cycles were repeated with the same procedure. After being used six cycles in successive reactions, still had a high catalytic performance, such as it is depicted in Fig. 6. Furthermore, FT-IR spectrum (Fig. 7) and XPS analysis (Fig. 8) of the recycled catalyst after six times revealed that this catalyst has a very high stability. In another experiment, after a $\sim 50 \%$ conversion of the reaction, the catalyst was removed from the reaction mixture. The analysis of reaction mixture showed that further performing of the reaction under optimum conditions in the absence of the catalyst did not show any significant progress. Also, ICP analysis of the reaction mixture demonstrated that the amount of Pd in the solution was less than the detection limit. Therefore, we can conclude that the designed catalyst has a truly heterogeneous nature. The heterogeneous character of the catalyst was further checked by a poisoning test using $\mathrm{S}_{8}$ as an efficient Pd scavenger. For this purpose, an aqueous mixture of nitrobenzene $(1 \mathrm{mmol}), \mathrm{NaBH}_{4}(3 \mathrm{mmol}), \mathrm{Pd}-\mathrm{NHC}-\gamma-\mathrm{Fe}_{2} \mathrm{O}_{3}-n$ butyl- $\mathrm{SO}_{3} \mathrm{H}(0.6 \mathrm{~mol} \%)$ and $\mathrm{S}_{8}(0.05 \mathrm{~g})$ was stirred at room temperature. Any product formation after $30 \mathrm{~min}$ clearly demonstrated its heterogeneous nature.

Having the results of nitro reduction in hand, we next examined the one-pot synthesis of imines by reduction of

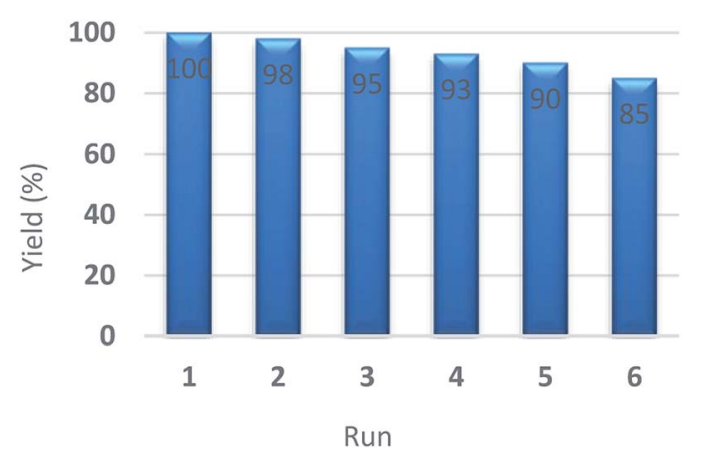

Fig. 6 The recycling efficiency of $\mathrm{Pd}-\mathrm{NHC}-\gamma-\mathrm{Fe}_{2} \mathrm{O}_{3}-n$-butyl $\mathrm{SO}_{3} \mathrm{H}$ in the reduction of nitrobenzene. nitrobenzene followed by Schiff base formation with benzaldehyde in aqueous media catalyzed by $\mathrm{Pd}-\mathrm{NHC}-\gamma-\mathrm{Fe}_{2} \mathrm{O}_{3}-n-$ butyl- $\mathrm{SO}_{3} \mathrm{H}$ as a bifunctional heterogeneous catalyst. As it is depicted in Table 3, the best yield of the imine was obtained in the presence of $1 \mathrm{~mol} \%$ of the catalyst (Table 3, entry 3). To demonstrate the catalyst function, similar reactions in the presence of Pd-NHC- $\gamma-\mathrm{Fe}_{2} \mathrm{O}_{3}-\mathrm{Me}$ and Pd-NHC- $\gamma-\mathrm{Fe}_{2} \mathrm{O}_{3}-\mathrm{SO}_{3} \mathrm{H}$ were examined. In both cases, nitrobenzene was fully converted to aniline after stirring for $30 \mathrm{~min}$. The imine was produced in higher yield in the presence of $\mathrm{Pd}-\mathrm{NHC}-\gamma-\mathrm{Fe}_{2} \mathrm{O}_{3}-\mathrm{SO}_{3} \mathrm{H}$ (entry 5). These results revealed that sulfonic acid can activate the aldehyde to undergo the reaction with the amine and produced imine in the second step of the reaction. Moreover, Pd-NHC- $\gamma$ $\mathrm{Fe}_{2} \mathrm{O}_{3}$-n-butyl- $\mathrm{SO}_{3} \mathrm{H}$ exhibited a higher catalytic efficiency than $\mathrm{Pd}-\mathrm{NHC}-\gamma-\mathrm{Fe}_{2} \mathrm{O}_{3}-\mathrm{SO}_{3} \mathrm{H}$ in the formation of imine, perhaps due to the presence of alkyl linker, which makes the acidic functional group more available.

To show the versatility and the wide scope of this protocol, a variety of nitroarenes were subjected to reduction-Schiff base condensation with arylaldehydes, yielding the corresponding imines. The results are summarized in Table 4 . The reaction of

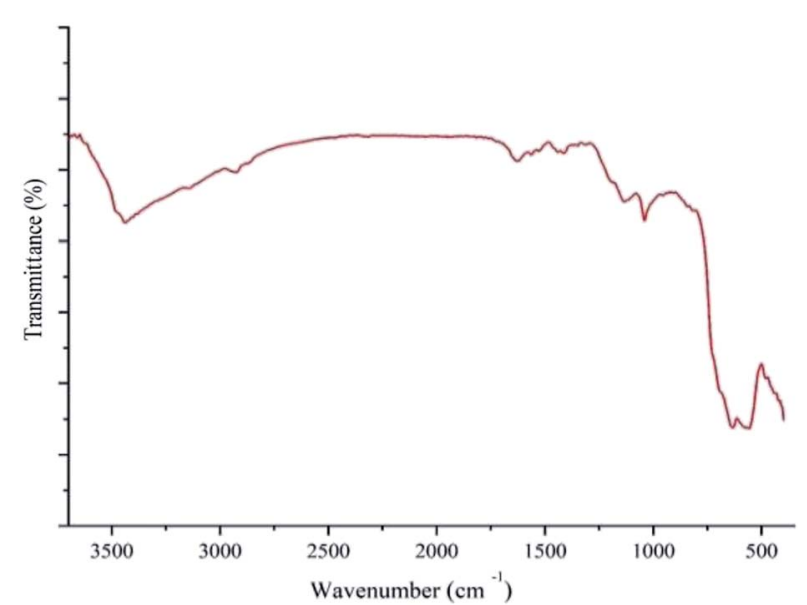

Fig. 7 FT-IR spectra of $\mathrm{Pd}-\mathrm{NHC}-\gamma-\mathrm{Fe}_{2} \mathrm{O}_{3}-n$-butyl- $\mathrm{SO}_{3} \mathrm{H}$ after six times reused. 

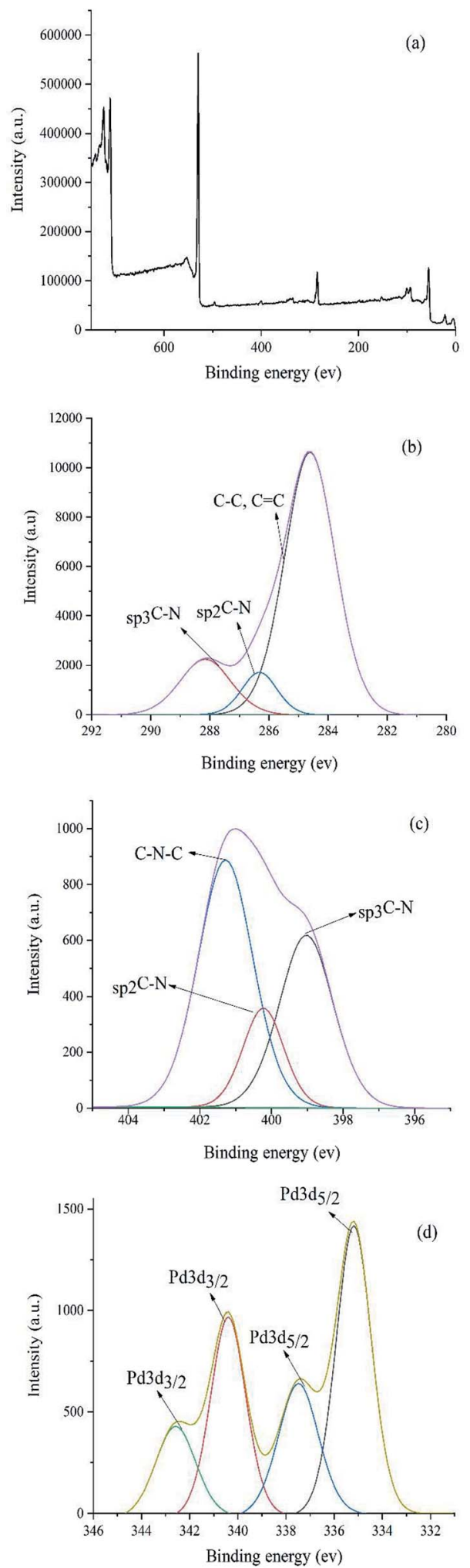

Fig. 8 (a) XPS patterns of $\mathrm{Pd}-\mathrm{NHC}-\gamma-\mathrm{Fe}_{2} \mathrm{O}_{3}-n$-butyl- $\mathrm{SO}_{3} \mathrm{H}$ after six times reused (b) $C$ 1s (c) N 1s (d) $P d$.

nitroarenes, bearing electron-donating groups at the aromatic ring, with benzaldehyde proceeded smoothly to afford the corresponding imines in high yields (Table 4, entries 1-3). However, nitroarenes, having electron-withdrawing groups at the aromatic ring, gave slightly lesser yields of the desired product during the reaction with benzaldehyde (Table 4, entries 4 and 5). This can be attributed to the lower nucleophilicity of these freshly formed amines. Other different substitutedbenzaldehydes (Table 4, entries 6-11), as well as heterocyclic aldehydes (Table 4, entries 12 and 13) were appropriate substrates to perform the reaction with nitrobenzene.

Further synthetic application of this mild reduction was demonstrated in other one-pot reaction involving carbonylation of the produced aniline derivatives with $\mathrm{Ac}_{2} \mathrm{O}$ or $\mathrm{Boc}_{2} \mathrm{O}$. The results of these studies are depicted in Table 5. The one-pot reduction-carbonylation of nitroarenes catalyzed by Pd-NHC$\gamma-\mathrm{Fe}_{2} \mathrm{O}_{3}-n$-butyl- $\mathrm{SO}_{3} \mathrm{H}$ under optimized reaction conditions proceeded well and produced the desired products in good to high yields, independently of the acylating agent.

Finally, the catalytic efficiency of Pd-NHC- $\gamma-\mathrm{Fe}_{2} \mathrm{O}_{3}-n$-butyl$\mathrm{SO}_{3} \mathrm{H}$ was compared with those of a number of previously reported catalysts for the reduction of nitroarenes, one-pot reduction-Schiff base condensation and one-pot reductioncarbonylation of nitroarenes (Table 6). The results showed that the previously reported catalytic systems were associated with several drawbacks such as high temperatures, the use of hazardous organic solvents or reagents, unrecoverable catalysts or inflammable hydrogen gas. Our catalysis method can eliminate almost all of these drawbacks, since Pd-NHC- $\gamma-\mathrm{Fe}_{2} \mathrm{O}_{3}-n$ butyl- $\mathrm{SO}_{3} \mathrm{H}$ acted as a magnetically recyclable catalyst, worked at room temperature in the presence of $\mathrm{NaBH}_{4}$ in neat water and without using any additive. Moreover, $\mathrm{Pd}-\mathrm{NHC}-\gamma-\mathrm{Fe}_{2} \mathrm{O}_{3}-n-$ butyl- $\mathrm{SO}_{3} \mathrm{H}$ is the most effective catalyst for the nitro-group reduction (Table 6, entries 1-5) for its operational simplicity, one-pot reduction-Schiff base condensation and one-pot reduction-carbonylation of nitroarene of TON (Table 6, entries 6-14).

This promising result should be attributed to the bifunctional catalysis of $\mathrm{Pd}-\mathrm{NHC}-\gamma-\mathrm{Fe}_{2} \mathrm{O}_{3}-n$-butyl- $\mathrm{SO}_{3} \mathrm{H}$ that enabled one-pot multistep reactions. The process involved reduction of the correspondent nitro compounds to anilines in the presence of the Pd catalyst and then reaction of anilines with the carbonyl compounds or anhydrides catalyzed by acidic functional group of Pd-NHC- $\gamma-\mathrm{Fe}_{2} \mathrm{O}_{3}-n$-butyl- $\mathrm{SO}_{3} \mathrm{H}$ to give imines and amides, respectively.

\section{Experimental}

\section{General information}

Chemicals were purchased from Merck Chemical Company. The purity of the products and the progress of the reactions were accomplished by TLC on silica gel polygram SILG/UV254 plates. FT-IR spectra were recorded on a Shimadzu Fourier Transform Infrared Spectrophotometer (FT-IR-8300). The content of Pd in the catalyst was determined by OPTIMA 7300DV ICP analyzer. TEM analysis was performed using TEM microscope (Philips EM 208S). Thermo-gravimetric analysis (TGA) was performed using a Shimadzu thermos-gravimetric analyzer (TG-50). Vibrating Sample Magnetometer (VSM) analysis was performed using VSM (Lake Shore Cryotronics 7407). Melting points were measured on an electrothermal 9100 
Table 3 One-pot reduction-Schiff base condensation of nitrobenzene with benzaldehyde in aqueous media

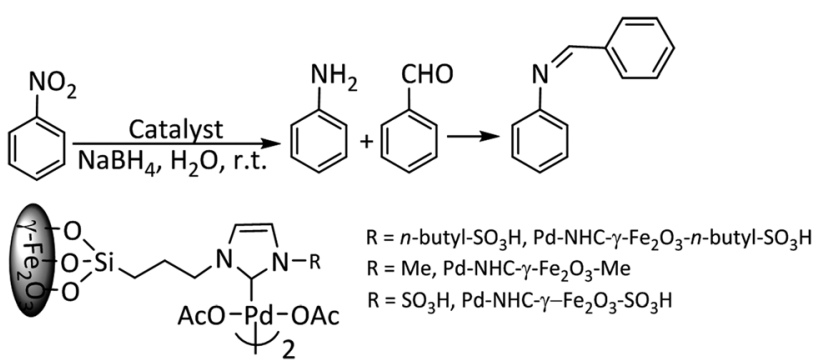

\begin{tabular}{llcc}
\hline Entry $^{a}$ & Catalyst (mol\%) & Time (min) & Isolated yield (\%) \\
\hline 1 & Pd-NHC- $\gamma-\mathrm{Fe}_{2} \mathrm{O}_{3}-n$-butyl- $\mathrm{SO}_{3} \mathrm{H}(0.6)$ & 70 & 76 \\
2 & $\mathrm{Pd}-\mathrm{NHC}-\gamma-\mathrm{Fe}_{2} \mathrm{O}_{3}-n$-butyl- $\mathrm{SO}_{3} \mathrm{H} \mathrm{(0.8)}$ & 70 & 80 \\
3 & $\mathrm{Pd}-\mathrm{NHC}-\gamma-\mathrm{Fe}_{2} \mathrm{O}_{3}-n$-butyl- $\mathrm{SO}_{3} \mathrm{H}(1)$ & 70 & 93 \\
4 & $\mathrm{Pd}-\mathrm{NHC}-\gamma-\mathrm{Fe}_{2} \mathrm{O}_{3}-\mathrm{Me}^{(1)}$ & 180 & 52 \\
5 & $\mathrm{Pd}-\mathrm{NHC}-\gamma-\mathrm{Fe}_{2} \mathrm{O}_{3}-\mathrm{SO}_{3} \mathrm{H}(1)$ & 180 & 83
\end{tabular}

${ }^{a}$ Nitrobenzene, $\mathrm{NaBH}_{4}$ (3 equiv.) and catalyst was stirred in aqueous media at room temperature for 30 min. Benzaldehyde (1.2 equiv.) was added to the stirring mixture.

apparatus. XPS analyses were performed using a VG-Microtech Multilab 3000 spectrometer, equipped with an $\mathrm{Al}$ anode. The deconvolution of spectra was carried out by using GaussianLorentzian curves.

\section{Synthesis of imidazole supported on $\gamma-\mathrm{Fe}_{2} \mathrm{O}_{3}\left(\gamma-\mathrm{Fe}_{2} \mathrm{O}_{3}\right.$-Im)}

The synthesized chloro-functionalized $\gamma-\mathrm{Fe}_{2} \mathrm{O}_{3}{ }^{21 e}(1.6 \mathrm{~g})$ was sonicated in dry toluene $(30 \mathrm{~mL})$ for $30 \mathrm{~min}$. Imidazole $(0.204 \mathrm{~g}, 3 \mathrm{mmol})$ was added to the stirring mixture and refluxed for $24 \mathrm{~h}$. After cooling, the mixture was stirred with $\mathrm{Et}_{3} \mathrm{~N}(0.43 \mathrm{~mL})$ for $30 \mathrm{~min}$ at room temperature. The solid was separated by an external magnet, washed with $\mathrm{H}_{2} \mathrm{O}(3 \times 10$ $\mathrm{mL})$ and acetone $(3 \times 10 \mathrm{~mL})$ and dried at $70{ }^{\circ} \mathrm{C}$ in oven under vacuum.

\section{Synthesis of $n$-butyl sulfonated $\gamma$ - $\mathrm{Fe}_{2} \mathrm{O}_{3}-\operatorname{Im}\left(\gamma-\mathrm{Fe}_{2} \mathrm{O}_{3}-\mathrm{Im}-n\right.$ - butyl- $\left.\mathrm{SO}_{3} \mathrm{H}\right)$}

The synthesized $\gamma-\mathrm{Fe}_{2} \mathrm{O}_{3}$-Im (1.5 g) was sonicated in dry toluene $(30 \mathrm{~mL})$ for $30 \mathrm{~min}$. 1,4-Butanesultone $(3 \mathrm{~mL})$ was added dropwise to the dispersed mixture and stirred at $90{ }^{\circ} \mathrm{C}$ for $24 \mathrm{~h}$. The solid was separated by an external magnet, washed with $\mathrm{H}_{2} \mathrm{O}(3 \times 10 \mathrm{~mL})$ and acetone $(3 \times 10 \mathrm{~mL})$ and dried at $70{ }^{\circ} \mathrm{C}$ in oven under vacuum. The synthesized solid $(1.5 \mathrm{~g})$ was added to $\mathrm{HCl}(25 \mathrm{~mL}, 0.1 \mathrm{M})$ and sonicated for $24 \mathrm{~h}$ at room temperature. The solid was separated by an external magnet, washed with $\mathrm{H}_{2} \mathrm{O}$ to reach pH 6-7 and dried at $70{ }^{\circ} \mathrm{C}$ in oven under vacuum.

Table 4 One-pot reduction-Schiff base condensation of nitroarenes with arylaldehydes catalyzed by $\mathrm{Pd}-\mathrm{NHC}-\gamma-\mathrm{Fe} \mathrm{O}_{3}-n-\mathrm{butyl}-\mathrm{SO}{ }_{3} \mathrm{H}$ as a bifunctional heterogeneous catalyst ${ }^{a}$

\begin{tabular}{|c|c|c|c|c|c|c|}
\hline Entry & Aldehyde & Nitroarene & Time (min) & Isolated yield (\%) & $\begin{array}{l}\text { Obtained } \\
\mathrm{mp}\left({ }^{\circ} \mathrm{C}\right)\end{array}$ & Reported mp $\left({ }^{\circ} \mathrm{C}\right)$ [ref.] \\
\hline 1 & Benzaldehyde & 3-Nitrophenol & 100 & 94 & 151 & $149[26]$ \\
\hline 2 & Benzaldehyde & 3-Nitrophenol & 110 & 98 & 192-194 & $197-198[27]$ \\
\hline 3 & 4-Chlorobenzene & 1-Methoxy-4-nitrobenzene & 110 & 87 & $124-125$ & $121-123[28]$ \\
\hline 4 & Benzaldehyde & 1-Bromo-4-nitrobenzene & 110 & 74 & $61-62$ & $62-63[27]$ \\
\hline 5 & Benzaldehyde & 1-Chloro-4-nitrobenzene & 110 & 71 & $58-60$ & $58-61[29]$ \\
\hline 6 & 2-Hydroxybenzaldehyde & Nitrobenzene & 130 & 92 & $51-52$ & $52-54[30]$ \\
\hline 7 & Benzaldehyde & Nitrobenzene & 70 & 93 & $47-49$ & $48-50[31]$ \\
\hline 8 & 4-Chlorobenzaldehyde & Nitrobenzene & 100 & 84 & $59-61$ & $60-61[31]$ \\
\hline 9 & 4-Cyanobenzaldehyde & Nitrobenzene & 90 & 86 & $94-95$ & $97-98[32]$ \\
\hline 10 & 4-Bromobenzaldehyde & Nitrobenzene & 100 & 75 & $75-77$ & $71-74[29]$ \\
\hline 11 & 2,4-Dichlorobenzaldehyde & Nitrobenzene & 180 & 87 & $74-76$ & $78-80[31]$ \\
\hline 12 & Nicotinaldehyde & Nitrobenzene & 180 & 90 & $19-20$ & $21.5[33]$ \\
\hline 13 & $1 H$-Indole-3-carboxaldehyde & Nitrobenzene & 240 & 60 & $128-130$ & $132[34]$ \\
\hline
\end{tabular}

${ }^{a}$ Nitroarene, $\mathrm{NaBH}_{4}$ (3 equiv.) and catalyst was stirred in aqueous media at room temperature for 30 min. Aldehyde (1.2 equiv.) was added to the stirring mixture. 
Table 5 One-pot reduction-carbonylation of nitroarenes catalyzed by $\mathrm{Pd}-\mathrm{NHC}-\gamma-\mathrm{Fe}_{2} \mathrm{O}_{3}-n-$ butyl-SO${ }_{3} \mathrm{H}$ as a bifunctional heterogeneous catalyst $^{a}$

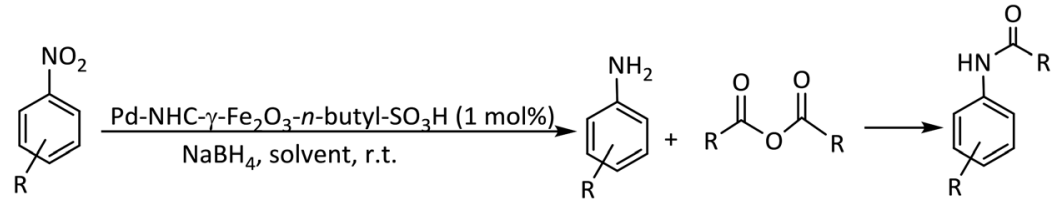

\begin{tabular}{|c|c|c|c|c|c|c|}
\hline Entry & Nitroarene & Anhydride & Time (min) & Isolated yield (\%) & $\begin{array}{l}\text { Obtained } \\
\mathrm{mp}\left({ }^{\circ} \mathrm{C}\right)\end{array}$ & Reported mp $\left({ }^{\circ} \mathrm{C}\right)$ [ref.] \\
\hline 1 & Nitrobenzene & $\mathrm{Ac}_{2} \mathrm{O}$ & 110 & 99 & $106-107$ & $108-111[35]$ \\
\hline 3 & 1-Methyl-4-nitrobenzene & $\mathrm{Ac}_{2} \mathrm{O}$ & 130 & 95 & $153-155$ & $152-154[35]$ \\
\hline 4 & 1-Methoxy-4-nitrobenzene & $\mathrm{Ac}_{2} \mathrm{O}$ & 75 & 93 & $125-126$ & $127-128[35]$ \\
\hline 5 & Nitrobenzene & $\mathrm{Boc}_{2} \mathrm{O}$ & 100 & 92 & $134-135$ & $134-136[36]$ \\
\hline 8 & 1-Chloro-4-nitrobenzene & $\mathrm{Boc}_{2} \mathrm{O}$ & 180 & 80 & $103-105$ & $104-106[36]$ \\
\hline
\end{tabular}

${ }^{a}$ Nitroarene, $\mathrm{NaBH}_{4}$ (3 equiv.) and catalyst was stirred in aqueous media at room temperature for 30 min. $\mathrm{Ac}_{2} \mathrm{O}$ or $\mathrm{Boc}_{2} \mathrm{O}(1.2$ equiv.) was added to the stirring mixture.

\section{Synthesis of Pd-NHC complex of $\gamma-\mathrm{Fe}_{2} \mathrm{O}_{3}$-Im-n-butyl-SO $\mathrm{S}_{3} \mathrm{H}$ (Pd-NHC- $\gamma-\mathrm{Fe}_{2} \mathrm{O}_{3}$-n-butyl-SO $\mathrm{S}_{3} \mathrm{H}$ )}

The synthesized $\gamma$ - $\mathrm{Fe}_{2} \mathrm{O}_{3}$-Im- $n$-butyl- $\mathrm{SO}_{3} \mathrm{H}(1 \mathrm{~g})$ was sonicated in DMSO $(15 \mathrm{~mL})$ for $30 \mathrm{~min} . \mathrm{Pd}(\mathrm{OAc})_{2}(0.5 \mathrm{mmol})$ was added to the dispersed mixture under $\mathrm{N}_{2}$ atmosphere at room temperature. The mixture was stirred for $6 \mathrm{~h}$ at $50^{\circ} \mathrm{C}$ and then allowed to proceed for an additional $4 \mathrm{~h}$ at $100{ }^{\circ} \mathrm{C}$. The resulting complex was collected by an external permanent magnet and washed with acetone $(3 \times 10 \mathrm{~mL})$ and $\mathrm{EtOH}(3 \times 10 \mathrm{~mL})$ to remove the unreacted $\mathrm{Pd}(\mathrm{OAc})_{2}$. The catalyst was obtained as dark-brown solid after drying at $70{ }^{\circ} \mathrm{C}$ in oven under vacuum.

\section{Methylation reaction of $\gamma-\mathrm{Fe}_{2} \mathrm{O}_{3}$-Im to synthesis $\gamma-\mathrm{Fe}_{2} \mathrm{O}_{3}$-Im-Me}

The synthesized $\gamma-\mathrm{Fe}_{2} \mathrm{O}_{3}$-Im ( $1 \mathrm{~g}$ ) was sonicated in dry toluene $(30 \mathrm{~mL})$ for $30 \mathrm{~min}$. Methyl iodide $(2 \mathrm{mmol})$ was added to the dispersed mixture and refluxed for $24 \mathrm{~h}$. The solid was separated by an external magnet, washed with $\mathrm{Et}_{2} \mathrm{O}(3 \times 10 \mathrm{~mL})$ and acetone $(3 \times 10 \mathrm{~mL})$ and dried in oven under vacuum.

\section{Synthesis of Pd-NHC of $\gamma$ - $\mathrm{Fe}_{2} \mathrm{O}_{3}$-Im-Me (Pd-NHC- $\left.\gamma-\mathrm{Fe}_{2} \mathrm{O}_{3}-\mathrm{Me}\right)$}

The synthesized $\gamma-\mathrm{Fe}_{2} \mathrm{O}_{3}$-Im-Me $(1 \mathrm{~g})$ was sonicated in DMSO $(15 \mathrm{~mL})$ for $30 \mathrm{~min}$. $\mathrm{Pd}(\mathrm{OAc})_{2}(0.5 \mathrm{mmol})$ was added to the dispersed mixture under $\mathrm{N}_{2}$ atmosphere at room temperature. The mixture was stirred for $6 \mathrm{~h}$ at $50{ }^{\circ} \mathrm{C}$ and then allowed to proceed for an additional $4 \mathrm{~h}$ at $100{ }^{\circ} \mathrm{C}$. The solid was separated by an external magnet, washed with $\mathrm{Et}_{2} \mathrm{O}(3 \times 10 \mathrm{~mL})$, acetone $(3 \times 10 \mathrm{~mL})$ and dried at $70{ }^{\circ} \mathrm{C}$ in oven under vacuum.

\section{Synthesis of sulfonated $\gamma-\mathrm{Fe}_{2} \mathrm{O}_{3}-\mathrm{Im}\left(\gamma-\mathrm{Fe}_{2} \mathrm{O}_{3}-\mathrm{Im}-\mathrm{SO}_{3} \mathrm{H}\right)$}

The synthesized $\gamma-\mathrm{Fe}_{2} \mathrm{O}_{3}$-Im (1 g) was sonicated in DMSO (30 $\mathrm{mL}$ ) for $30 \mathrm{~min}$. Chlorosulfonic acid $(3 \mathrm{~mL})$ was slowly added dropwise to the dispersed mixture in an ice-bath and stirred for $24 \mathrm{~h}$ at room temperature. The solid was separated by an external magnet, washed with $\mathrm{H}_{2} \mathrm{O}$ to reach $\mathrm{pH}$ 6-7 and dried at $70{ }^{\circ} \mathrm{C}$ in oven under vacuum.

\section{Synthesis of Pd-NHC of $\gamma-\mathrm{Fe}_{2} \mathrm{O}_{3}-\mathrm{Im}-\mathrm{SO}_{3} \mathrm{H}\left(\mathrm{Pd}-\mathrm{NHC}-\gamma-\mathrm{Fe}_{2} \mathrm{O}_{3}-\right.$ $\mathrm{SO}_{3} \mathrm{H}$ )}

The synthesized $\gamma-\mathrm{Fe}_{2} \mathrm{O}_{3}-\mathrm{Im}-\mathrm{SO}_{3} \mathrm{H}(1 \mathrm{~g})$ was sonicated in DMSO $(15 \mathrm{~mL})$ for $30 \mathrm{~min}$. $\mathrm{Pd}(\mathrm{OAc})_{2}(0.5 \mathrm{mmol})$ was added to the dispersed mixture under $\mathrm{N}_{2}$ atmosphere at room temperature. The mixture was stirred for $6 \mathrm{~h}$ at $50{ }^{\circ} \mathrm{C}$ and then allowed to proceed for an additional $4 \mathrm{~h}$ at $100{ }^{\circ} \mathrm{C}$. The solid was separated by an external magnet, washed with $\mathrm{Et}_{2} \mathrm{O}(3 \times 10 \mathrm{~mL})$, acetone $(3 \times 10 \mathrm{~mL})$ and dried at $70{ }^{\circ} \mathrm{C}$ in oven under vacuum.

\section{General procedure for reduction of nitroarenes}

$\mathrm{Pd}-\mathrm{NHC}-\gamma-\mathrm{Fe}_{2} \mathrm{O}_{3}-n$-butyl-SO ${ }_{3} \mathrm{H}(0.028 \mathrm{~g}, 0.6 \mathrm{~mol} \%)$ was added to the stirring mixture of nitrobenzene $(1 \mathrm{mmol})$ in $\mathrm{H}_{2} \mathrm{O}(2 \mathrm{~mL})$. $\mathrm{NaBH}_{4}(3 \mathrm{mmol})$ was added in two portions with the interval of 2 min between them, and the resulting mixture was continued to stir at room temperature for the appropriate time (see Table 2). EtOAc $(5 \mathrm{~mL})$ was added to the reaction mixture. $\mathrm{Pd}-\mathrm{NHC}-\gamma-$ $\mathrm{Fe}_{2} \mathrm{O}_{3}-n$-butyl- $\mathrm{SO}_{3} \mathrm{H}$ was separated by an external magnet and washed with EtOAc $(2 \times 5 \mathrm{~mL}), \mathrm{H}_{2} \mathrm{O}(3 \times 10 \mathrm{~mL})$ and acetone $(3$ $\times 10 \mathrm{~mL}$ ). The combined organic layer was then dried over anhydrous $\mathrm{Na}_{2} \mathrm{SO}_{4}$. Evaporation of the solvent under reduced pressure gave the crude products. The pure products were isolated by chromatography on silica gel eluted with $n$-hexane:EtOAc $(4: 1)$.

\section{General procedure for the one-pot reduction-Schiff base formation from nitroarenes}

$\mathrm{Pd}-\mathrm{NHC}-\gamma-\mathrm{Fe}_{2} \mathrm{O}_{3}-n$-butyl- $\mathrm{SO}_{3} \mathrm{H}(1 \mathrm{~mol} \%)$ was added to the stirring mixture of nitrobenzene $(1 \mathrm{mmol})$ in $\mathrm{H}_{2} \mathrm{O}(2 \mathrm{~mL}) . \mathrm{NaBH}_{4}(3$ $\mathrm{mmol}$ ) was added in two portions with the interval of $2 \mathrm{~min}$ 
between them, and the mixture was stirred at room temperature for $30 \mathrm{~min}$. Next, aryl aldehyde $(1.2 \mathrm{mmol})$ was added to the mixture and stirred for the appropriate time (see Table 4). EtOAc $(5 \mathrm{~mL})$ was added to the reaction mixture. Pd-NHC- $\gamma-\mathrm{Fe}_{2} \mathrm{O}_{3}-n-$ butyl- $\mathrm{SO}_{3} \mathrm{H}$ was separated by an external magnet and washed with EtOAc $(2 \times 5 \mathrm{~mL}), \mathrm{H}_{2} \mathrm{O}(3 \times 10 \mathrm{~mL})$ and acetone $(3 \times 10$ $\mathrm{mL})$. The combined organic layer was then dried over anhydrous $\mathrm{Na}_{2} \mathrm{SO}_{4}$. Evaporation of the solvent under reduced pressure gave the crude products. The pure products were isolated by chromatography on silica gel eluted with $n$-hexane : EtOAc $(4: 1)$.

\section{General procedure for the one-pot reduction-carbonylation of nitroarenes}

$\mathrm{Pd}-\mathrm{NHC}-\gamma-\mathrm{Fe}_{2} \mathrm{O}_{3}-n$-butyl- $\mathrm{SO}_{3} \mathrm{H}(1 \mathrm{~mol} \%)$ was added to the mixture of nitrobenzene $(1 \mathrm{mmol})$ in $\mathrm{H}_{2} \mathrm{O}(2 \mathrm{~mL}) . \mathrm{NaBH}_{4}(3$ $\mathrm{mmol}$ ) was added in two portions with the interval of $2 \mathrm{~min}$ between them, and the mixture was vigorously stirred at room temperature for $30 \mathrm{~min}$. $\mathrm{Ac}_{2} \mathrm{O}$ or $\mathrm{Boc}_{2} \mathrm{O}(1.2 \mathrm{mmol})$ was added to the mixture and stirred for an appropriate time (see Table 5). EtOAc $(5 \mathrm{~mL})$ was added to the reaction mixture. Pd-NHC- $\gamma$ $\mathrm{Fe}_{2} \mathrm{O}_{3}$-n-butyl- $\mathrm{SO}_{3} \mathrm{H}$ was separated by an external magnet and washed with EtOAc $(2 \times 5 \mathrm{~mL}), \mathrm{H}_{2} \mathrm{O}(3 \times 10 \mathrm{~mL})$ and acetone $(3$ $\times 10 \mathrm{~mL}$ ). The combined organic layer was then dried over anhydrous $\mathrm{Na}_{2} \mathrm{SO}_{4}$. Evaporation of the solvent under reduced pressure gave the crude products. The pure products were isolated by chromatography on silica gel eluted with $n$-hexane : EtOAc $(5: 3)$.

\section{Conclusions}

We have demonstrated the successful synthesis of Pd-NHC- $\gamma$ $\mathrm{Fe}_{2} \mathrm{O}_{3}$-n-butyl- $\mathrm{SO}_{3} \mathrm{H}$ as a bifunctional heterogeneous nanomagnetic catalyst containing $\mathrm{Pd}-\mathrm{NHC}$ and acidic functional groups. This newly synthesized catalyst was characterized by different methods such as FT-IR, XPS, TEM, VSM, ICP and TG analysis. Pd-NHC- $\gamma-\mathrm{Fe}_{2} \mathrm{O}_{3}-n$-butyl- $\mathrm{SO}_{3} \mathrm{H}$ was successfully used as a new heterogeneous catalyst for the reduction of nitroarenes using $\mathrm{NaBH}_{4}$ as a clean source of hydrogen generation in aqueous media at ambient temperature. The catalytic activity of $\mathrm{Pd}-\mathrm{NHC}-\gamma-\mathrm{Fe}_{2} \mathrm{O}_{3}-n$-butyl- $\mathrm{SO}_{3} \mathrm{H}$ as a bifunctional heterogeneous catalyst was also evaluated in two one-pot protocols including reduction-Schiff base condensation and reduction-carbonylation of various nitroarenes. In these two reactions, amines formed in situ, using $\mathrm{NaBH}_{4}$ as a clean source of hydrogen generation, in aqueous media at ambient temperature and further reacted with aldehydes to yield imines or carbonylated to amides. By this protocol, a variety of imines and amides were obtained in good to high yields. The magnetic nature of the catalyst allows its facile recovery using an external magnetic field. The catalyst was separated efficiently and reused for six consecutive cycles without any drastic loss of its reactivity. Truly heterogeneous nature of the catalyst was proved by removing the catalyst after $50 \%$ progress of the reaction and poisoning test. The structure of the catalyst remained intact after six recoveries according to the FT-IR spectrum and XPS analysis of 
the used catalyst. Bifunctional catalysis of $\mathrm{Pd}-\mathrm{NHC}-\gamma-\mathrm{Fe}_{2} \mathrm{O}_{3}-n$ butyl- $\mathrm{SO}_{3} \mathrm{H}$ enabled one-pot multistep reactions without requiring product isolation in each step, using water as a green reaction media and $\mathrm{NaBH}_{4}$ as a clean source of hydrogen generation, which is safer than hydrogen gas. True heterogeneous nature and simple and efficient recyclability of the catalyst makes the present methodology sustainable and economic. The employment of this NHC-based system is in its developmental stage. The synthesis and properties of $\mathrm{Pd}-\mathrm{NHC}-\gamma-\mathrm{Fe}_{2} \mathrm{O}_{3}-$ $n$-butyl- $\mathrm{SO}_{3} \mathrm{H}$ exhibited in this work offers valuable opportunities for further advancements in this field of study.

\section{Conflicts of interest}

There are no conflicts to declare.

\section{Acknowledgements}

We gratefully acknowledge the University of Birjand Research Council and the University of Alicante for the financial support of this study.

\section{References}

1 M. J. Climent, A. Corma and S. Iborra, Chem. Rev., 2011, 111, 1072.

2 (a) J. D. Bass and A. Katz, Chem. Mater., 2006, 18, 1611; (b) B. Voit, Angew. Chem., Int. Ed., 2006, 42, 4238.

3 (a) K. Motokura, N. Fujita, K. Mori, T. Mizugaki, K. Ebitani, K. Jitsukaea and K. Kaneda, Chem.-A Eur. J., 2006, 12, 8228; (b) K. Mori, Y. Kondo, S. Morimoto and H. Yamashita, Chem. Lett., 2007, 36, 1068; (c) E. L. Margelefsky, R. K. Zeidan and M. E. Davis, Chem. Soc. Rev., 2008, 37, 1118.

4 (a) K. Motokura, M. Tomita, M. Tada and Y. Iwasawa, Chem.A Eur. J., 2008, 14, 4017; (b) R. K. Zeidan, S. J. Hwang and M. E. Davis, Angew. Chem., 2006, 118, 6480; (c) R. K. Zeidan and M. E. Davis, J. Catal., 2007, 247, 379.

5 (a) O. Schuster, L. Yang, H. G. Raubenheimer and M. Albrecht, Chem. Rev., 2009, 109, 3445; (b) P. de Frémont, N. Marion and S. P. Nolan, Coord. Chem. Rev., 2009, 253, 862; (c) S. Budagumpi, R. A. Haque and A. W. Salman, Coord. Chem. Rev., 2012, 256, 1787.

6 (a) X. X. Wang, B. B. Xu, W. T. Song, K. X. Sun and J. M. Lu, Org. Biomol. Chem., 2015, 13, 4925; (b) H. Lv, L. Zhu, Y. Q. Tang and J. M. Lu, Appl. Organomet. Chem., 2014, 13, 27; (c) C. del Pozo, A. Corma, M. Iglesias and F. Sánchez, J. Catal., 2012, 291, 110; (d) L. Zhu, Y. M. Ye and L. X. Shao, Tetrahedron, 2012, 68, 2414; (e) W. X. Chen and L. X. Shao, J. Org. Chem., 2012, 77, 9236.

7 (a) Q. H. Fan, Y. M. Li and A. S. C. Chan, Chem. Rev., 2002, 102, 3385; (b) N. E. Leadbeater and M. Marco, Chem. Rev., 2002, $102,3217$.

8 (a) S. Kim, H. J. Cho, D. S. Shin and S. M. Lee, Tetrahedron Lett., 2017, 58, 2421; (b) B. Karimi and D. Enders, Org. Lett., 2006, 8, 1237; (c) M. Ghotbinejad, A. R. Khosropour, I. MohammadpoorBaltork, M. Moghadam, S. Tangestaninejad and V. Mirkhani, J.
Mol. Catal. A: Chem., 2014, 385, 78; (d) J. W. Byun and Y. S. Lee, Tetrahedron Lett., 2004, 45, 1837.

9 (a) K. V. S. Ranganath and F. Glorius, Catal. Sci. Technol., 2011, 1, 13; (b) M. K. Samantaray, M. M. Shaikh and P. Ghosh, Organometallics, 2009, 28, 2267; (c) E. TomasMendivil, R. Garcia-Alvarez, C. Vidal, P. Crochet and V. Cadierno, ACS Catal., 2014, 4, 1901; (d) H. Ohara, W. W. N. O, A. J. Lough and R. H. Morris, Dalton Trans., 2012, 41, 8797; (e) G. Guillena, D. J. Ramon and M. Yus, Chem. Rev., 2010, 110, 1611.

10 (a) N. Sakai, K. Fujii, S. Nabeshima, R. Ikeda and T. Konakahara, Chem. Commun., 2010, 46, 3173; (b) K. Junge, B. Wendt, N. Shaikh and M. Beller, Chem. Commun., 2010, 46, 1769; (c) J. Yang, M. Yuan, H. Zhao, Y. Zhu, M. Fan, F. Zhang and Z. Dong, J. Mater. Chem. A., 2018, 6, 18242; (d) X. Cui, Y. Long, X. Zhou, G. Yu, J. Yang, M. Yuan, J. Ma and Z. Dong, Green Chem., 2018, 20, 1121.

11 L. L. Santos, P. Serna and A. Corma, Chem.-A Eur. J., 2009, 15, 8196.

12 A. Korich and T. Hughes, Synlett, 2007, 16, 2602.

13 X. Liu, S. Lan, C. Li, Y. Gao, J. Yan and X. Zhang, J. Chem. Res., 2014, 38, 16.

14 Y. Zheng, K. Ma, H. Li, J. He, X. Sun, R. Li and J. Ma, Catal. Lett., 2009, 128, 465.

15 T. Song, P. Ren, Y. Duan, Z. Wang, X. Chen and Y. Yang, Green Chem., 2018, 20, 4629.

16 E. M. Nahmed and G. Jenner, Tetrahedron Lett., 1991, 32, 4917.

17 B. H. Kim, R. Han, F. Piao, Y. M. Jun, W. Baik and B. M. Lee, Tetrahedron Lett., 2003, 44, 77.

18 B. Zeynizadeh, R. Younesi and H. Mousavi, Res. Chem. Intermed., 2018, 44, 7331.

19 K. Basu, S. Chakraborty, C. Saha and A. K. Sarkar, IOSR J. Appl. Chem., 2014, 7, 30.

20 Z. Shokri, B. Zeynizadeh and S. A. Hosseini, J. Colloid Interface Sci., 2017, 485, 99.

21 (a) S. Sobhani, Z. M. Falatooni, S. Asadi and M. Honarmand, Catal. Lett., 2016, 146, 255; (b) S. Sobhani, Z. Zeraatkar and F. Zarifi, New J. Chem., 2015, 39, 7076; (c) S. Sobhani, S. Asadi and F. Zarifi, J. Organomet. Chem., 2016, 822, 154; (d) S. Sobhani and Z. Ramezani, RSC Adv., 2016, 6, 29237; (e) S. Sobhani, Z. Mesbah Falatooni and M. Honarmand, RSC Adv., 2014, 4, 15797.

22 (a) M. Zhao, Y. Cao, X. Liu, J. Deng, D. Li and H. Gu, Nanoscale Res. Lett., 2014, 9, 142; (b) S. Wang, J. Zhang, P. Yuan, Q. Sun, Y. Jia, W. Yan, Z. Chen and Q. Xu, J. Mater. Sci., 2015, 5, 1323.

23 B. Zeynizadeh and F. Sepehraddin, J. Iran. Chem. Soc., 2017, $14,2649$.

24 Y. S. Feng, J. J. Ma, Y. M. Kang and H. J. Xu, Tetrahedron, 2014, 70, 6100.

25 O. Mazaheri and R. J. Kalbasi, RSC Adv., 2015, 5, 34398.

26 K. J. Al-Adilee, S. M. Eassa and H. K. Dakhil, Orient. J. Chem., 2016, 32, 2481.

27 R. Suresh, D. Kamalakkannan, K. Ranganathan, R. Arulkumaran, R. Sundararajan, S. P. Sakthinathan, S. Vijayakumar, K. Sathiyamoorthi, V. Mala, 
G. Vanangamudi, K. Thirumurthy, P. Mayavel and G. Thirunarayanan, Spectrochim. Acta, Part A, 2013, 101, 239. 28 A. Jarrahpour, P. Shirvani, V. Sinou, C. Latour and J. M. Brunel, Med. Chem. Res., 2016, 25, 149.

29 K. Tanaka and R. Shiraishi, RSC Adv., 2000, 2, 272.

30 M. G. Dekamin, M. Azimoshan and L. Ramezani, Green Chem., 2013, 15, 811.

31 R. Rezaei, M. K. Mohammadi and T. Ranjbar, E-J. Chem., 2011, 8, 1142.

32 C. Yijima, T. Tsujimoto, K. Suda and M. Yamauchi, Bull. Chem. Soc. Jpn., 1986, 89, 2165.
33 K. Maeder and E. Fischer, Helv. Chim. Acta, 1983, 7, 1961.

34 W. Imhof, J. Organomet. Chem., 1997, 533, 31.

35 M. Gupta and M. Gupta, J. Iran. Chem. Soc., 2015, 13, 231. 36 N. Azizi and F. Shirdel, Monatsh. Chem., 2016, 148, 1069.

37 Q. Yang, Y. Z. Chan, Z. U. Wang, Q. Wu and H. L. Jiang, Chem. Commun., 2015, 51, 10419.

38 Z. Li, J. Li, J. Li, Z. Zhao, C. Xia and F. Li, ChemCatChem, 2014, 6, 1333.

39 K. Azizi, E. Ghonchepour, M. Karimi and A. Heydari, Appl. Organomet. Chem., 2015, 29, 187. 